\title{
Comparative Study of Intermaxillary Relationships of Manual and Swallowing Methods
}

\author{
Márcia Cristina ALVAREZ 1 \\ Miriam Lacale TURBINO² \\ Celso de BARROS ${ }^{3}$ \\ Valéria Oliveira PAGNANO ${ }^{1}$ \\ Osvaldo Luiz BEZZON ${ }^{1}$ \\ ${ }^{1}$ Department of Dental Materials and Prosthodontics, Dental School of Ribeirão Preto, \\ University of São Paulo, Ribeirão Preto, SP, Brazil \\ ${ }^{2}$ Department of Restorative Dentistry, Dental School, University of São Paulo, São Paulo, SP, Brazil \\ ${ }^{3}$ School of Dentistry, University of Tiradentes, Aracaju, SE, Brazil.
}

\begin{abstract}
This study compared the mandibular displacement from three methods of centric relation record using an anterior jig associated with (A) chin point guidance, (B) swallowing (control group) and (C) bimanual manipulation. Ten patients aged 25-39 years were selected if they met the following inclusion criteria: complete dentition (up to the second molars), Angle class I and absence of signs and symptoms of temporomandibular disorders and diagnostic casts showing stability in the maximum intercuspation (MI) position. Impressions of maxillary and mandibular arches were made with an irreversible hydrocolloid impression material. Master casts of each patient were obtained, mounted on a microscope table in MI as a reference position and 5 records of each method were made per patient. The mandibular casts were then repositioned with records interposed and new measurements were obtained. The difference between the two readings allowed measuring the displacement of the mandible in the anteroposterior and lateral axes. Data were analyzed statistically by ANOVA and Tukey's test at 5\% significance level. There was no statistically significant differences ( $p>0.05)$ among the three methods for measuring lateral displacement $(\mathrm{A}=0.38 \pm 0.26, \mathrm{~B}=0.32 \pm 0.25$ and $\mathrm{C}=0.32 \pm 0.23)$. For the anteroposterior displacement $(A=2.76 \pm 1.43, B=2.46 \pm 1.48$ and $C=2.97 \pm 1.51)$, the swallowing method $(B)$ differed significantly from the others $(p<0.05)$, but no significant difference $(p>0.05)$ was found between chin point guidance $(A)$ and bimanual manipulation $(C)$. In conclusion, the swallowing method produced smaller mandibular posterior displacement than the other methods.
\end{abstract}

Key words: centric relation, chin point guidance, swallowing, bimanual manipulation.

\section{INTRODUCTION}

The establishment of harmony between the simultaneous bilateral maximal intercuspation (MI) of the teeth and the temporomandibular joint (TMJ) is a goal that has been searched for decades (1). For several clinicians, an ideal occlusal relationship would be the one in which no interceptive occlusal contact occurs on mouth closing with a terminal hinge movement and no sliding, indicating the existence of a stable physiological relationship in the condyle-disk assembly (1). In this situation, the centric relation (CR) and MI coincide (2).
As the rotation axis between the mandibular condyles is already established, reproducing it in such a way to achieve harmony between dental anatomy and condylar position has caused many changes in the recording methods $(3,4)$. This search has led to controversial findings in the literature $(5,6)$ and difficulties in the understanding of the procedure by clinicians.

CR research has been done over 50 years (7). Historically, CR has several definitions (5) but it remains a classic reference position of the relationship between the maxillary and mandibular arches for occlusal and TMJ examination and prosthetic treatment $(5,6,8,9)$.

Correspondence: Prof. Dr. Osvaldo Luiz Bezzon, Departamento de Materiais Dentários e Prótese, Faculdade de Odontologia de Ribeirão Preto, USP, Avenida do Café, s/n, 14040-904 Ribeirão Preto, SP, Brasil. Tel: +55-16-3602-4334. Fax: +55-16-3633-0999. e-mail: olbezzon@forp.usp.br 
There are a wide variety of recording methods for reproducing the physiological intermaxillary relationship $(8,10)$. These methods have limitations and are classified depending on whether the operator guides the mandible or the patients uses their own muscular action (5), swallowing $(6,8)$, and transcutaneous nervous stimulation, denominated myocentric $(11,12)$. All methods have been widely investigated and have received criticism for their use due to either anterior positioning (myocentric analysis) (7) or lack of reproducibility (swallowing) $(7,13)$.

Physiological stability of the mandible is obtained during swallowing only when the closing arch is free from occlusal interference (8). Therefore, Lucia (14) has proposed the use of an anterior jig, as a muscular deprogrammer to eliminate dental interference during the recording. The method that uses bimanual manipulation is considered reproducible $(7,15,16)$, but there is no scientifically based evidence that it is better than the method that uses chin point manipulation (17). In view of this, the purpose of this study was to compare the mandibular displacement from three methods of centric relation record using an anterior jig associated with chin point guidance, swallowing and bimanual manipulation.

\section{MATERIAL AND METHODS}

Ten patients aged 25 to 39 years were selected for this study if they met the following inclusion criteria: (1) complete dentition (up to the second molars); (2) Angle class I; (3) absence of signs and symptoms of temporomandibular disorders (TMD); and (4) diagnostic casts showing stability in the MI position. The study design was approved by the local Research Ethics Committee (Protocol \# 2003.1.910.58.3).

Impressions of maxillary and mandibular arches were obtained with an irreversible hydrocolloid impression material (Jeltrate; L.D. Caulk-Dentsply, Milford, DE, USA), and poured with stone die (Vel-Mix; Kerr, Emeryville, CA, USA). The maxillary casts were positioned with the occlusal surface upwards with their bases attached to a plastic device fixed on a microscope table (model ZKM 02-250; Carl Zeiss, Jena, Germany) by the addition of a stone die standard cylinder, which was made from a plastic matrix.

A line was drawn on the base of the mandibular casts, extending from the line between the central incisors and to the center of the distance between the lines drawn from the center of the occlusal surface of the molars. A metallic rod $(0.5 \mathrm{~mm}$ diameter and $2.0 \mathrm{~mm}$ long), was attached to the center of the line drawn on the base of the casts. The mandibular cast was articulated in MI with the maxillary cast. This assembly was positioned so that the line drawn in the base of the mandibular cast overlaid the $y$ axis and the metallic rod on the crossing of the $\mathrm{x}$ and $\mathrm{y}$ axes of the measurement gauge. The values were read on the microscope display at this point. The MI position was adopted as a reference position for displacement measurement of the three studied techniques.

Five records were obtained for each patient. One of each type of recording method was obtained in each session. The patient was neuromuscular deprogrammed with an anterior jig with plane distal platform, obtained by using an indirect method in the stone die, which had sufficient opening to promote desocclusion. The jig was used for 15 min before obtaining the jaw relationship recordings. After deprogramming, the methods of CR record were performed as described in the following paragraphs.

Technique A was the chin point guidance: before making the record, a small portion of acrylic resin (Duralay; Reliance Dental MFG Co., Worth, Ill, USA) was prepared and placed on the area where the mandibular incisor would touch the jig in CR. The operator then gently jiggled the chin point and guided the mandible closure until the mandibular incisors were touching the jig, creating a key position for reference at the moment of the interocclusal record in CR. A slightly heated wax plate was positioned in the patient's mouth (from canines to second molars) and the operator guided the mandible until the mandibular incisors found the key position previously registered in the jig. After cooling, the wax plate was carefully removed and perforated at the locations of the first molars. These perforations were filled with acrylic resin, the record was placed in the correct position and the patient was asked to close the mouth until the mandibular incisors touched the key position. The patient continued to hold this position until the material set. This procedure promoted three rigid points (the anterior jig and two posterior points - wax plate and resin) (18) to guide the positioning of the mandibular cast on the maxillary cast (Fig. 1), which had already been attached to the microscope table. The measurements were taken at this point 
For each of the 5 sessions, a new key position was obtained on the anterior jig.

Technique B was the control group, that is, the swallowing method: with the patient's body in a supine position, the anterior jig was positioned by asking the patient to open the mouth and attempt to close and swallow at the exact moment when the anterior teeth touched the jig. At this moment, the patient was asked to hold tight, while the operator injected the interocclusal record material (Occlufast; Zhermack SPA, Rovigo, Italy) between the occlusal surfaces, from the buccal side of the second molars to the buccal side of the canines. The patient continued to hold this position until the material set. Thereafter, the record was removed, the excesses were cut in order to adapt the mandibular cast to the maxillary cast, previously attached to the microscope table, and the mandibular cast was positioned on the record. No key position was made in the anterior jig in the 5 sessions. The measurements were then taken.

Technique $\mathrm{C}$ was the bimanual manipulation

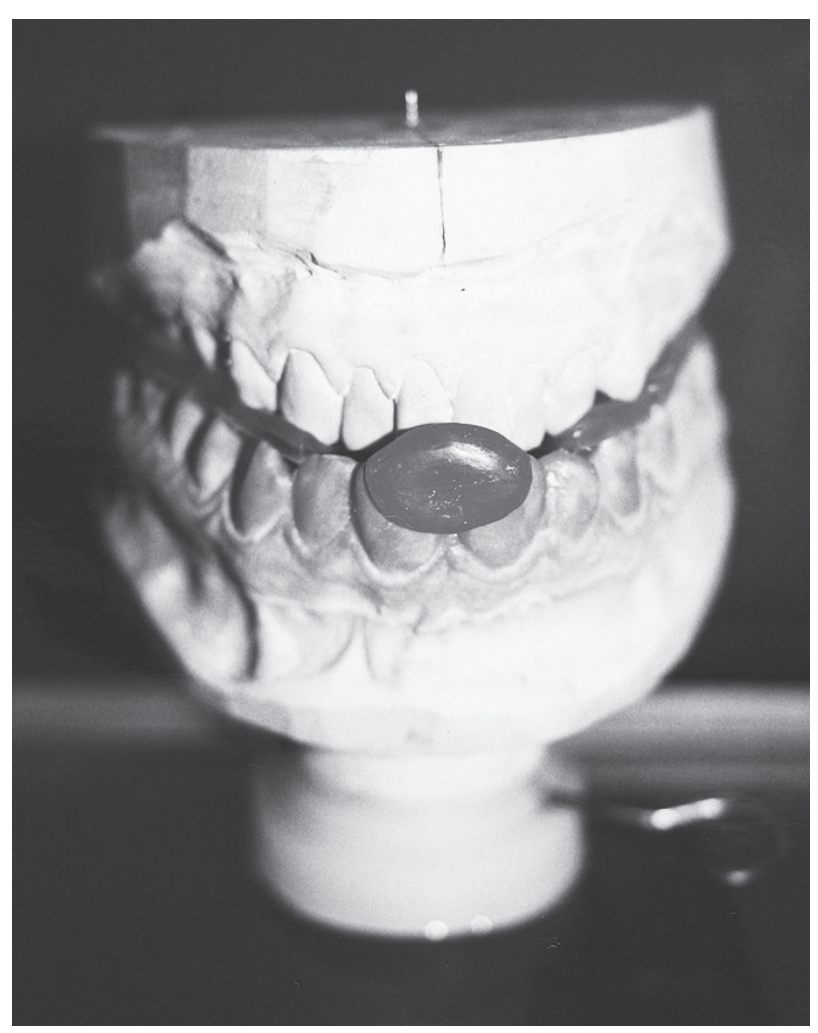

Figure 1 . The mandibular cast articulated with maxillary cast by means of jig and wax record. method, originally proposed by Dawson (15), and was similar to technique A. When the records were interposed, it was possible to see the displacement of the metallic rod of the mandibular cast in relation to the crossing of the $\mathrm{x}$ and $\mathrm{y}$ axes of the measurement matrix through the lenses. The microscope was disengaged and a new centralization of the reference points was made. The new values were read on the display, indicating the displacement of the mandibular cast in relation the maxillary cast. Figure 2 shows the complete sequence of the measurements. The difference between the two readings enabled determining the degree

A

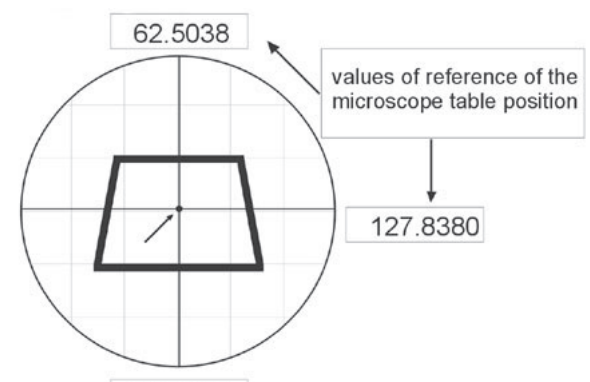

B
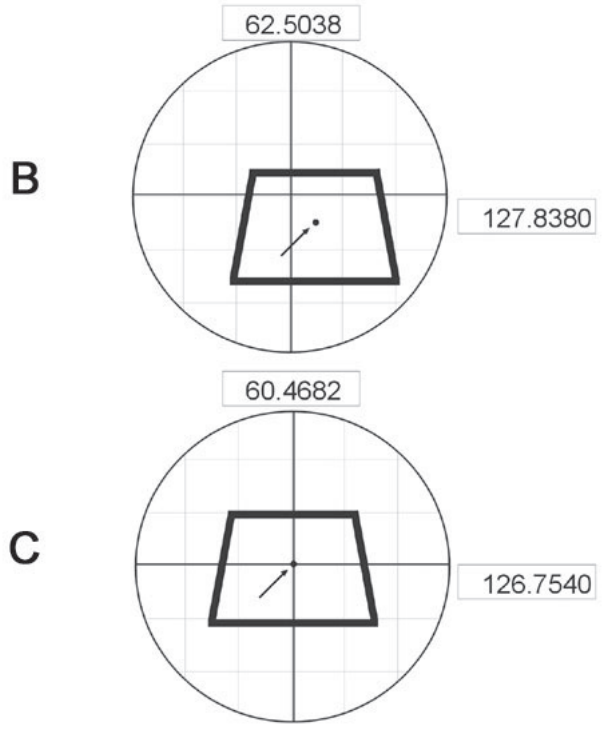

Figure 2. Schematic presentation of the displacement measurements on the mandibular cast. A, casts related in MI centralized in the measurement form (central rod coincident with the crossing of the axes $\mathrm{x}$ and $\mathrm{y}$ and midline coincident with axis $\mathrm{y})$; B, displacement of the mandibular cast as a consequence of the record interposition; $\mathrm{C}$, realignment of the casts with the references of the measurement form. Notice the alteration of the position values of the microscope table. 
of the anteroposterior (A-P) displacement for the $\mathrm{x}$ axis and the lateral (L) displacement for the y axis.

The data were subjected to 2-way analysis of variance and Tukey's test at 5\% significance level.

\section{RESULTS}

Tables 1 and 2 show the mean values and standard deviations (SD) of the differences determined by the displacement from MI to the positions resulting from the 5 records obtained for each of the 3 evaluated methods.

Table 1 presents the results of the lateral displacement (L). There was no statistically significant difference ( $p>0.05)$ among the methods for recording lateral displacement. Table 2 shows the anteroposterior (A-P) displacement. The swallowing method (B) differed significantly from the others $(\mathrm{p}<0.001)$, but no significant difference $(p>0.05)$ was found between chin point guidance (A) and bimanual manipulation (C).

\section{DISCUSSION}

Currently, CR is defined as a maxillomandibular relationship in which the condyles articulate with the thinnest avascular portion of their respective disks, with the complex in the anterior-superior position against the shapes of the articular eminence (19). This position is independent of tooth contact and is clinically discernable when the mandible is directed superiorly and anteriorly $(1,5,19)$. However, since there have been controversies and confusions have arisen in the clinicians' understanding (5-7). Nevertheless, it is both the most important and critic relationship among all of the intermaxillary relationships because failures in its acquisition may cause disharmony. This disharmony will compromise the rehabilitation with the most sophisticated treatments, even though the stomatognathic system's struc-

Table 1. Lateral displacement of the methods ( $\mathrm{mm})$.

\begin{tabular}{ll}
\hline \multicolumn{1}{c}{ Methods } & Mean \pm SD \\
\hline Chin point guidance & $0.38^{\mathrm{a}} \pm 0.26$ \\
Swallowing & $0.32^{\mathrm{a}} \pm 0.25$ \\
Bimanual manipulation & $0.32^{\mathrm{a}} \pm 0.23$ \\
\hline
\end{tabular}

Same letters indicate no statistically significant difference $(\alpha=0.05)$. tures are seen as susceptible to constant remodeling and hence is not completely stable by itself (15). This absence of consensus regarding the ideal mandibular position created gaps that ended up being filled by countless methods, intended to obtain the CR in a proper, reproducible and precise manner.

In the conditions of this study, the horizontal relationship of the casts was used as a reference, and as a manner to estimate the mandibular position, similar to the clinical conditions. The anterior position of the mandibular cast was found by using the swallowing method (the control group), compared to the chin point guidance and bimanual manipulation methods, which is confirmed by having the smallest average of the measurement A-P. Therefore, this position is closer to MI and is more appropriate than the position obtained with the other evaluated methods. These results are in agreement with those of other studies $(6,13)$.

The swallowing technique was largely commented and criticized by some authors for its great variability $(7,13)$. Considering the results obtained in this study and reported in the literature (8), the use of an anterior jig has contributes to reduce this variation.

The greatest average of posterior displacement of the mandibular cast was obtained with the bimanual manipulation method, not having a significant difference for the values obtained with the chin point guidance method. The mandibular retrusion observed with these two techniques compared to the swallowing method, does not mean that the movement was the same in the TMJ. It may be suggested that the condyle had rotated inside the mandibular fossa, adjusting more in the anterior direction against the articular eminence, with the disk interposed. This position might have lead the mandible to a more retrusive position.

There was no difference in the values obtained for the lateral displacement with any of the three methods evaluated.

Table 2. Antero-posterior displacement of the methods (mm).

\begin{tabular}{ll}
\hline \multicolumn{1}{c}{ Methods } & Mean \pm SD \\
\hline Chin point guidance & $2.76^{\mathrm{a}} \pm 1.43$ \\
Swallowing & $2.46^{\mathrm{b}} \pm 1.48$ \\
Bimanual manipulation & $2.97^{\mathrm{a}} \pm 1.51$ \\
\hline
\end{tabular}

Different letters indicate statistically significant difference $(\alpha=0.05)$. 
The main problem for interpreting the results of the different methods evaluated here is the absence of a pattern for comparison. Without the knowledge of the correct CR position, it is impossible to determine which method provides the best results, since reproducibility is often confused with great physiological capacity (4).

Due to the need of reestablishing an occlusal scheme from a clinical point of view, it is necessary to make a first decision concerning the mandibular position to be adopted as a basis for therapy (20). The use of an ideal mandibular position, which suits the previously establishedtheoretical patterns, certainly is not the best choice for the occlusal therapy. On the other hand, the use of a MI position under the argument that, for instance, there is no symptomatology, may maintain one or both condyles dangerously out of their places.

Since there is need of intervention, the clinician should usually ignore the mandibular position guided by the teeth and should allow the condyles to fit properly in the mandibular fossa, with the articular disk correctly interposed. Research to define this position has been done for a long time. However, defining RC may not even be the most important issue. The argument for a more superior and posterior, superior and anterior, or more superior is not valid. The key point is that the condyle is located in the mandibular fossa and may thus provide the exact position because nobody can force the mandible upward or forward. Therefore, from a teaching point of view, the most important concept is to have the condyle in the position designed for it, with the disk properly interposed, without compression of any area and with minimal activity of the lateral pterygoid muscles to ensure that they did not have to support the condyle anteriorly.

The re-establishment of the occlusal scheme do not depend on time-related adaptations but rather will be integrated and in accordance with the remaining tissues of the masticatory system, at the moment of treatment, and will be able to carry out its function with the least expense of energy.

The use of a temporary prosthesis may adjust the patient's need to reach a healthy condition through suitable physiological function $(1,2)$. After the initial stabilization and the concomitant reduction of signs and symptoms, the treatment plan may then be completed (1). This is a learning process for the clinician and a training process for the patient. The re-establishment of the occlusal scheme, using the $\mathrm{CR}$ as a point of reference, allows the clinician to evaluate the progress and treatment outcome.

$\mathrm{CR}$ is thus of major clinical significance since it allows a mandibular position in relation to the maxilla, which is not guided by a poor occlusal relationship. It is thus possible to agree with Sutcher (4), who stated that reproducibility does not warrant the physiological nature of $\mathrm{CR}$, but the validity of the position should be recognized. The clinical success that is verified in different studies of different methods is the proof that good sense is present in the clinical approach of oral rehabilitation.

A method or device that, properly regulated, would lead the mandible to a position that is reproducible and physiologically accepted by the patient, is strongly favorable. In practice, however, it is necessary that the professional develops the ability to use a method that provides convenience and critical sense to evaluate the results.

Among the three methods evaluated, the swallowing method is extremely dependent on the patient and may cause incorrect position when there is an occlusal interference. The methods which use manipulation did not cause a difference in the position of the mandibular cast, in relation to the maxillary cast. When applied in combination with the use of anterior protections, anterior jig or leaf gauge, these methods ensure that the condyle is correctly adjusted without the reflex arch determined by the proprioceptor system.

Considering the employed methodology and within the limitations of this study, it may be concluded that the swallowing method produced smaller mandibular posterior displacement than the other methods.

\section{RESUMO}

Este estudo comparou o deslocamento mandibular a partir de 3 métodos de registro da relação cêntrica usando um jig anterior associado com: (A) guia da ponta do mento; (B) deglutição grupo controle (C) manipulação bimanual. As moldagens dos arcos maxilares e mandibulares foram feitas com hidrocolóide irreversível. Os modelos de estudo de cada paciente foram obtidos e montados em máxima intercuspidação como uma posição de referência no microscópio. Foram obtidos 5 registros de cada método em 10 pacientes. Os modelos mandibulares foram reposicionados com os registros interpostos e novas medidas foram obtidas. A diferença entre as duas leituras permitiu a medida do deslocamento mandibular nos eixos ântero-posterior e laterais. ANOVA não demonstrou diferença estatisticamente significativa entre os 3 métodos em relação ao registro do deslocamento lateral $(\mathrm{A}=0,38 \pm 0,26, \mathrm{~B}=0,32 \pm 0,25 \mathrm{e} \mathrm{C}=0,32$ 
$\pm 0,23)$. Quanto ao deslocamento anteroposterior, ANOVA e o teste de Tukey $(\alpha=0,05)$ indicaram diferença estatisticamente significante entre os três métodos $(\mathrm{A}=2,76 \pm 1,43, \mathrm{~B}=2,46 \pm 1,48$ $\mathrm{e} C=2,97 \pm 1,51)$. Não houve diferença estatisticamente significante entre A e C. A deglutição propiciou menor deslocamento mandibular posterior que os outros métodos.

\section{REFERENCES}

1. Keough B. Occlusion-based treatment planning for complex dental restorations: Part 1. Int J Periodontics Restorative Dent $2003 ; 23: 237-247$.

2. Wood GN. Centric relation and the treatment position in rehabilitating occlusions: a physiologic approach. Part II: The treatment position. J Prosthet Dent 1988;60:15-18.

3. Obrez A, Turp JC. The effect of musculoskeletal facial pain on registration of maxillomandibular relationships and treatment planning: a synthesis of the literature. J Prosthet Dent 1998;79:439-445.

4. Sutcher H. The contraindication of restoration to centric relation: a clinical report. J Prosthet Dent 1996;75:588-590.

5. Dixon DL. Overview of articulation materials and methods for the prosthodontic patient. J Prosthet Dent 2000;83:235247.

6. Abdel-Hakim AM. The swallowing position as a centric relation record. J Prosthet Dent 1982;47:12-15.

7. Keshvad A, Winstanley RB. An appraisal of the literature on centric relation. Part I. J Oral Rehabil 2000;27:823-833.

8. Campos AA, Nathanson D, Rose L. Reproducibility and condylar position of the physiologic maxillomandibular centric relation in upright and supine body position. J Prosthet Dent
1996;76:282-287.

9. Türp JC, Greene CS, Strub JR. Dental occlusion: a critical reflection on past, present and future concepts. J Oral Rehabil 2008;35:446-453.

10. Bodere C, Woda A. Effect of a jig on EMG activity in different orofacial pain conditions. Int J Prosthodont 2008;21:253-8.

11. Baba K, Tsukiyama Y, Clark GT. Reliability, validity, and utility of various occlusal measurement methods and techniques. J Prosthet Dent 2000;83:83-89.

12. Keshvad A, Winstanley RB. An appraisal of the literature on centric relation. Part III. J Oral Rehabil 2001;28:55-63.

13. Celar AG, Kundi M, Piehslinbger E, Fürhauser R, Kohlmaier B. Mandibular position at chin-point guided closure, intercuspation and final deglutition in asymptomatic and temporomandibular dysfunction subjects. J Oral Rehabi 2000;27:70-78.

14. Lucia VO. Modern gnathological concepts - updated. Chicago: Quintessence Publishing Co, Inc, 1983.

15. Dawson PE. Relation centric. Its effect on occluso-muscle harmony. Dent Clin North Am 1979;23:169-180.

16. Keshvad A, Winstanley RB. Comparison of the replicability of routinely used centric relation registration techniques. J Prosthodont 2003;12:90-101.

17. Ash MM. Philosophy of occlusion: past and present. Dent Clin North Am 1995;39:233-255.

18. Bezzon OL, Orsi IA. An interocclusal record made of a combination of wax and acrylic resin. J Prosthet Dent 1994;72:334336.

19. The Glossary of Prosthodontic Terms Seventh Edition. J Prosthet Dent 1999;81:39-110.

20. Christensen GJ. Is occlusion becoming more confusing? A plea for simplicity. J Am Dent Assoc 2004,135:767-770.

Accepted September 11, 2008 